\title{
SCHILLER E A CONTINUIDADE IDEALISTA NA TEORIA DO REALISMO BURGUÊS ALEMÃo
}

\author{
Daniel Bonomo \\ Universidade Estadual de Campinas
}

\section{Resumo}

O ensaio procura mostrar manutenções idealistas em textos do realismo programático alemão na década de 1850 buscando no pensamento de Schiller, em fins do século XVIII, escolhas e conteúdos atualizados em Theodor Fontane, Otto Ludwig e Julian Schmidt, três dos principais nomes da teoria realista em apreço, também conhecida como teoria do realismo burguês. A opção por determinadas conciliações, nesses autores, conduz o debate.

\section{Abstract}

This article attempts to show idealistic continuities in German programmatic realism during the 1850's decade by referring back to Schiller's thought of the late 18th Century in search for choices and contents that were restored by Theodor Fontane, Otto Ludwig and Julian Schmidt, three crucial names of the theory in question, also known as theory of bourgeois realism. The option for certain conciliations in these authors leads the debate.

\author{
Palavras-chave \\ Idealismo; \\ realismo; \\ Friedrich Schiller; \\ Theodor Fontane; \\ Otto Ludwig; \\ Julian Schmidt.
}

Keywords

Idealism;

realism;

Friedrich Schiller;

Theodor Fontane;

Otto Ludwig;

Julian Schmidt. 


\section{Introdução}

Antes de qualquer coisa, esclareço o título: trata-se de perceber em Schiller ideias e um idealismo de certo modo conservados pela teoria do realismo literário de língua alemã. Não são ideias só de Schiller, está claro. Schiller parece fornecer contudo elementos bons para a compreensão dessas continuidades: primeiro, elevado à condição de poeta nacional e embaixador da liberdade, permanece em discussões e aproveitamentos literários do século XIX de muitas formas, especialmente festejado em 1859, centenário de seu nascimento; depois, Schiller é um dos principais responsáveis por transpor o termo "realismo", então sobretudo filosófico, para o domínio artístico.

Também explico a presença da expressão "realismo burguês", de cunho sociológico. Já a precisão sociológica e política incluiria uma variedade de condições (burgueses liberais, progressistas, conservadores); além disso, a expressão unifica autores não sempre burgueses. ${ }^{1}$ Mas, com "realismo burguês", quero assinalar seu uso recorrente na historiografia literária ${ }^{2} \mathrm{e}$ não confundir com um realismo textual, "sistemático" (como preferem os alemães) ou construtivo. O realismo burguês seria, portanto, um "realismo histórico". Na periodização tradicional da literatura alemã, compreende a segunda metade do século XIX, separado da literatura da época Vormärz justamente pela revolução refreada de 1848.

Ainda com relação ao título, falar da presença do idealismo no realismo histórico não consiste exatamente em novidade. $\mathrm{O}$ assunto é conhecido dos pesquisadores do período. A escolha de Schiller como representante idealista tampouco surpreende em razão de uma carta endereçada a Goethe, em abril de 1798, em que comenta ser traço comum e predominante nos franceses o uso do entendimento (Verstand) e de atributos intelectuais como a observação e o chiste, que os tornariam mais sensíveis à realidade física, menos à realidade moral: "Das ist keine Frage, daß sie bessere Realisten als Idealisten sind, und ich nehme daraus ein siegendes Argument, daß der Realism keinen Poeten machen kann". ${ }^{3}$ Quer dizer, segundo Schiller, franceses seriam antes realistas que idealistas, e realismo não resultaria em poetas.

A afirmação consta de um documento privado, consiste numa confissão para um amigo, não é propriamente cuidadosa, por um lado, como são seus pensamentos teóricos feitos para a divulgação, mas, por outro, mostra convicção. Surge, aliás, pouco após a conclusão do estudo sobre as poesias ingênua e sentimental, em que expõe mais completamente sua noção de realismo. É sempre bom lembrar que Schiller não conhece a ideia de realismo literário formada com o século XIX. "Realismo", em Schiller, não se vincula tão diretamente à cultura literária sem passar por significados filosóficos.

\section{Schiller entre idealismo e realismo}

O ensaio de Schiller sobre as poesias ingênua e sentimental surge a partir de 1795 e será publicado em sua forma integral em 1800 (Kleinere prosaische Schriften). No contexto da estética alemã de fins do século XVIII, o texto de Schiller é contribuição fundamental para a diferenciação entre o antigo e o moderno. Os conceitos principais são o ingênuo (das Naive) e o sentimental (das Sentimentalische). Não são excludentes e não estão circunscritos a épocas determinadas - o antigo não é sempre ingênuo e o moderno pode não ser de todo sentimental. 
O ingênuo é próprio da natureza e em parte da arte clássica, é necessário e espontâneo. O gênio é e tem de ser ingênuo. O sentimental, próprio da arte moderna, é livre e racional. A arte é já distância da natureza, mas busca a natureza. Os poetas, para Schiller, ou são natureza ou buscam a natureza; são ingênuos no primeiro caso e sentimentais no segundo. Não insisto porém nessa distinção que, afinal, é suficientemente conhecida. Passo a outra distinção, presente no ensaio, porém menos comentada, a saber, a entre realistas e idealistas.

Trata-se de uma distinção "característica" dos homens ou distinção entre dois tipos de Menschencharaktere. ${ }^{4}$ Essa distinção domina as últimas páginas do ensaio recorrendo aos termos "idealismo" e "realismo". Como se vê, é também uma distinção moral, à semelhança do que ocorre com o ingênuo e o sentimental, o par realista/idealista. Porque Schiller fala sobretudo em "maneiras de sentir" (Empfindungsweise). Sua poética coloca em primeiro plano não a obra de arte, mas a relação do homem com a obra de arte. Também não está em primeiro plano o objeto da obra de arte, ainda que seja decisivo.

Com referência ao "caráter", Schiller diz perceber um "antagonismo psicológico" que separa os homens, em sua época e em todas as épocas, e que não permite que sejam universais nem como poetas nem como filósofos, uma insuficiência também daqueles a que chama ingênuos e sentimentais. A poesia aproxima ingênuos e sentimentais, quer dizer, é o que têm em comum. Logo, sem a poesia, como ficam ingênuos e sentimentais? No ingênuo, de acordo com Schiller, sem a poesia, sobra o realista; no sentimental, o idealista. O primeiro obedece à necessidade da natureza, o segundo, à da razão.

Schiller, como teórico, não quer privilegiar nenhum dos dois tipos, embora seja confessadamente idealista - aliás, se toma Goethe por realista, é porque sabe de suas qualidades. ${ }^{5}$ Diz considerar ambos, realista e idealista, "em seu sentido mais digno e em toda a plenitude de seu conceito". 6 Schiller esboça na verdade uma epistemologia e uma ética a partir das diferenças e complementaridades dos tipos realista e idealista, compensando vantagens e desvantagens de um e outro. Por exemplo, o idealista pode aproximar-se mais facilmente do universal, mas também mais facilmente desentenderá o singular, ao contrário do realista; o realista pode desculpar o "vulgar" (das Gemeine) e o "baixo" (das Niedrige), mas não o "excêntrico", ao passo que o idealista é "inimigo" do trivial e pode desculpar o "extravagante". São complementares como experiência (realista) e razão (idealista), mas insuficientes como "ideal da natureza humana".

Além disso, realistas e idealistas devem ser, segundo Schiller, "verdadeiros". O "verdadeiro realista" obedece à natureza como um todo; o "falso realista", por sua vez, "crê e compreende apenas aquilo que toca", 7 sua parcialidade é a de um "empirista vulgar"; o falso idealista, diferentemente do verdadeiro idealista, que abandona a natureza pela razão e atrás do imutável, o falso idealista deixa a natureza por simples capricho, seu comportamento arbitrário revela um "fantasista". São duas formas de corrupção, por assim dizer, o empirista e o fantasista.

Mas nem tudo em Schiller aponta para a conciliação. Talvez seja possível perceber escolhas que privilegiam enfim, no texto em questão, a atitude idealista. A meu ver, sobressaem três aspectos dessa atitude que compromete o realismo de Schiller: o primeiro diz respeito a uma avaliação negativa do presente; o segundo a uma dificuldade, na representação artística, com o elemento baixo; e o terceiro a uma polaridade, que se impõe como argumento, separando o "verdadeiro" do "falso" e o "verdadeiro" do "real". No que respeita à avaliação do 
presente, o sentimento dominante provém de uma "imagem medonha da época". ${ }^{8}$ Schiller não hesita em qualificar sua época mediante expressões como "mundo corrompido" (verderbte Welt) ou "relações artificializadas" (gekünstelte Verhältnissen). São expressões que supõem relações naturais e um mundo anterior à corrupção. Mais que isso: supõem a possibilidade de escapar - procurando a natureza - e reagir a essa corrupção. O "amigo sentimental da natureza" (empfindsamer Freund der Natur) não renuncia à vida ou não se resigna completamente:

\begin{abstract}
Pergunta-te, quando a arte te repugna e és impelido à solidão da natureza inanimada pelos abusos da sociedade, se o que nesta abominas são as espoliações, os encargos, as dificuldades ou a anarquia moral, o arbítrio, as desordens. Tua coragem tem de arremeter com alegria contra aqueles abusos e tua compensação tem de ser a própria liberdade de onde eles provêm. [...] nada de queixas contra a complicação da vida, contra a desigualdade das condições, contra a pressão das circunstâncias, contra a incerteza da posse, contra ingratidão, opressão, perseguição; tens de submeter-te, com livre resignação, a todos os males da cultura. ${ }^{9}$
\end{abstract}

A ideia de uma "resignação livre" (freie Resignation) sugere conservar, no íntimo, a liberdade e a lei acima da confusão da cultura. Mas, apesar do conselho sobre a manutenção da alegria, é indubitável a profusão de termos negativos com que se adverte dos "abusos da sociedade". O trecho só permanece dúbio porque, como quem precisa afirmar a boa disposição, Schiller também trai, nessa profusão de atributos, seu interesse na realidade ruim.

Com respeito à recusa e o estranhamento do elemento baixo - o segundo aspecto dos três que mencionei -, os momentos são vários. ${ }^{10} \mathrm{O}$ assunto evidencia um estágio importante nesta mudança dos hábitos literários tão vinculada ao século XVIII. Schiller relata, por exemplo, um incômodo já em suas primeiras leituras de Shakespeare, quando não compreendia bem a presença de um gracejo em situação de páthos elevado. Em Schiller, no ensaio em questão, mesmo gêneros que têm por objeto elementos baixos, como a sátira e a comédia, devem preservar o ideal. A sátira, diz Schiller, tem por objeto a realidade como "falta" (Mangel) e "aversão" (Abneigung), mas essa aversão só será poesia como contraparte do ideal, se estiver em contradição com o ideal e demandar o ideal. A comédia, por sua vez, por preferir um objeto baixo, exige um poeta livre de paixões e pronto para sustentar a "altura estética" (ästhetische Höhe) de seu objeto, alimentando igualmente o ideal.

Algo semelhante ocorre com o romance. Quer dizer, romance aqui não é propriamente poesia. Schiller diz que o romance é "meio-irmão" da poesia e "toca demasiadamente a terra". A proximidade excessiva do chão, no romance, só se justifica como ingenuidade e natureza, nunca como propósito, e se for "humanidade", isto é, se resultar do homem como um todo. Para Schiller, portanto, “[...] o mesmo poeta que pode permitir-se que participemos de sentimentos humanos tão baixos tem, por outro lado, de saber nos reerguer a tudo o que é humanamente grande e belo e sublime". ${ }^{11}$

Exigências assim, ou seja, de manter a elevação apesar ou justamente em razão do assunto baixo, encaminham para o terceiro e último aspecto: o recurso argumentativo das oposições. Já me referi à diferença entre os "verdadeiros" realistas e idealistas de Schiller e os "falsos", os empiristas e fantasistas. Há, além dessa, a diferença entre o "real" e o "verdadeiro". O real pode ser baixo, mas o verdadeiro é sempre nobre. O poeta está autorizado, segundo Schiller, a pintar um "quadro fiel da realidade" desde que seja "natureza humana verdadeira": 
Ai de nós, leitores, se a careta se espelha na careta, se o açoite da sátira cai nas mãos daquele a quem a natureza destina um chicote ainda mais severo; se homens que, desprovidos de tudo o que se chama espírito poético e possuindo somente o talento simiesco da imitação vulgar, exercitam-no cruel e terrivelmente à custa de nosso gosto! ${ }^{12}$

O conceito de poesia de Schiller no ensaio consiste em "dar à humanidade a sua expressão mais completa possível". Ser a plenitude, como poeta ingênuo, imitando a natureza de maneira mais ou menos imediata, ou buscar a completude, como sentimental, mediado pela ideia e pela reflexão. A tarefa do sentimental é "elevar a realidade ao ideal"; 13 a poesia "tem de possuir um conteúdo infinito"; 14 a realidade seria limitada, o pensamento não. Passo aos realistas alemães do século XIX.

\section{Meios-termos no realismo histórico}

$\mathrm{Na}$ segunda metade do século XIX, os autores responsáveis pela teoria do realismo literário na Alemanha parecem concordar ao menos com relação à possibilidade de "reduzir", por assim dizer, a imagem de certo modo translúcida, o essencial da realidade histórica. Permanece praticamente ponto pacífico, entre os autores do realismo burguês, a reprodução de algo substancial e identitário, que reside na realidade histórica, mas que só a poesia, em sentido amplo, faz ver e manifestar os sentidos.

A partir da década de 1850, em meios literários, a palavra da vez será "realismo", noção em princípio oposta à contida no termo "idealismo". Mas, no entendimento teórico-literário dos principais realistas desse período - e me refiro àqueles que se adiantaram como defensores de um programa realista -, nesses realistas não se recusa exatamente o fundamento idealista da manifestação de algo essencial. No geral, a opção será por um realismo a meia distância entre um idealismo construído no ar (que recusam, grosso modo, nos românticos) e um naturalismo fotográfico (que recusam na mera cópia ou "imitação" da realidade), isto é, nem tanto ao mar nem tanto à terra, um realismo de meias medidas. Assim, ficariam preservados o senso, o vínculo com a realidade, mas também o arbítrio, a imaginação e o critério artístico.

Há um conjunto de documentos que demonstra essa opção. Sobretudo a discussão estética de tradição filosófica debate nesse momento o conflito realismo/idealismo. ${ }^{15}$ As especificidades desse debate, porém, não são agora mais relevantes que sua continuação no chamado "realismo programático", ou seja, naqueles que defenderam o realismo como programa literário. Como a matéria é ampla (e o estudo ainda breve) ${ }^{16}$ refiro rapidamente três posições centrais, as de Theodor Fontane, Otto Ludwig e Julian Schmidt, sem insistir em suas diferenças, apenas observando com que expedientes e qual idealismo mantêm. ${ }^{17}$

O principal texto de Fontane sobre os "novos tempos realistas" é de 1853 (Unsere lyrische und epische Poesie seit 1848). Aqui o realismo é entendido como uma realidade de sua época: na ciência, na política, nas questões materiais e principalmente na arte. Com relação à arte, na verdade, uma realidade não apenas de sua época. Desse texto consta a afirmação de que o realismo na arte "é tão antigo quanto a própria arte e mais: ele é a arte". ${ }^{18}$ A sentença não propõe um realismo fora da história, senão um realismo trans-histórico, quer dizer, a permanência de realismos diferentes em diferentes momentos históricos. Não se trata tampouco de perceber realismos formais ou de relativizar os realismos segundo circunstâncias 
e contingências diversas. A história e a história da arte em Fontane, ao menos no texto em questão, obedece a rígidas leis de necessidade: realismos são melhores ou piores segundo a época que os produz, e o seu tempo seria necessariamente melhor - porque avançou no conhecimento da realidade -, estaria necessariamente mais apto para o realismo que os tempos passados. O pensamento não implica só progressões lineares na aquisição de conhecimentos. Seu tempo retomaria, nesse sentido, movimentos realistas iniciados em meados do século XVIII, iniciados com Lessing e praticados também por Goethe e Schiller em sua obra primeira; seu tempo corrigiria, nesse mesmo sentido, um "sentimentalismo" e supostas "confusões" observadas na literatura alemã das décadas imediatamente anteriores.

A literatura realista imediatamente anterior à da geração de Fontane é recusada por supostos artificialismo, nudez e prosaísmo. A censura à nudez tem um sentido moral e deve ser compreendida como restrição nos conteúdos também por sua moral. Fontane fala em realismo "saudável". A ideia é que não sejam confundidos o realismo e a representação da feiura e da miséria (um "proletário moribundo" ou "tecelões silesianos", por exemplo). Não a coisa bruta, mas a matéria depurada ou decantada compõe o realismo de Fontane; a matéria "transfigurada" (Verklärung é reconhecidamente a palavra-chave neste contexto).O realismo é finalmente definido por Fontane como "reflexo de toda a vida real no elemento da arte", representação do minúsculo e do maiúsculo, do "pensamento elevado" e da "dor profunda", todos "reais":

$\mathrm{O}$ realismo não quer apenas o mero mundo sensível; quer menos ainda a coisa meramente palpável, mas a verdade. $\mathrm{O}$ realismo nada exclui senão a mentira, a contrafeição, o nebuloso, o morto - quatro coisas com que acreditamos qualificar toda uma época literária. ${ }^{19}$

A verdade interessa igualmente a Otto Ludwig, responsável, no contexto do realismo burguês, pela expressão "realismo poético". ${ }^{20}$ Com ela, Otto Ludwig procura acima de tudo distinguir um "realismo artístico" de um "realismo naturalista". A ideia é assegurar, nesse realismo artístico ou poético, um mundo autônomo, recriado, produto da fantasia ou do "entendimento da fantasia", ${ }^{21}$ mas não um mundo fantástico ou disparatado. Pelo contrário, autonomia, para Otto Ludwig, significa transparência nas relações de causalidade, que permitiria, em ficção, mais clareza que no mundo real. Também se nota, nesse mesmo sentido, a importância conferida às ideias de totalidade e unidade, que no realismo poético surgiriam igualmente visíveis, resolvidas em harmonia e contraste. Fundamental no pensamento de Otto Ludwig é aliás esse processo de visualização, "tornar visível” (sichtbar machen), endossando uma noção de realidade como fundo ou ventre que se revela.

Otto Ludwig distingue ainda do "realismo artístico" um "idealismo artístico". Idealistas porém, a seu ver, seriam tão restritos quanto naturalistas. Se o naturalista privilegia a variedade, o idealista prefere a unidade, à medida que o realismo poético aproximaria, numa espécie de "centro" (künstlerische Mitte), as duas tendências. Mas a crítica ao idealismo de Otto Ludwig não significa recusa à tradição idealista. Sua recusa tem antes que ver com um sentido específico do termo - também conhecido dos dias atuais e não de todo injusto, ainda que circunscrito -, isto é, idealismo como nefelibatismo, como devaneio e castelos no ar.

Algo parecido ocorre com Julian Schmidt, no que respeita à recusa do idealismo. Julian Schmidt foi editor, ao lado de Gustav Freitag (autor de Soll und Haben, best-seller em sua 
época), do periódico Die Grenzboten, que se tornou o veículo central para a promoção do realismo literário na década de 1850 na Alemanha. São vários os textos de Julian Schmidt aí publicados em defesa do realismo. E não faltam a esses textos críticas ao idealismo. Algumas dessas críticas dizem respeito a Schiller diretamente. Em 1851, por exemplo, Schmidt observava que o tempo presente se opunha ao anterior, que denominava "fase do idealismo subjetivo", rompendo com determinadas "ilusões", com determinado "universalismo diletante" e uma "infinidade falsa", que resulta de certo "sentimentalismo", termo imediatamente associado a Schiller. ${ }^{22}$ O "autêntico sentimentalismo", diz Schmidt, é produto do século XVIII. Para Schmidt, dividir a história da poesia nos "períodos" ingênuo e sentimental, como faz Schiller, é já consequência desse sentimentalismo. O ingênuo seria, portanto, uma invenção do sentimental, ou uma "reação" do sentimental. O argumento é justo e não desautoriza Schiller: para Schiller, os franceses inventaram a ideia de naïf, por exemplo, porque seriam justamente os mais distanciados da natureza pela civilização, os que foram "mais longe no inatural e na reflexão". ${ }^{23}$

Mas a relação de Schmidt com Schiller é no mínimo suspeita. Se, de um lado, Julian Schmidt não ignora a contribuição de Schiller para um idealismo que ele recusa por associar o ideal com o possível deitando "um abismo" entre o real e o possível, de outro lado, em texto posterior (1858), Schiller será considerado também um "realista". ${ }^{24}$ Para Schmidt, Schiller "aprendeu" seu idealismo, mas o realismo nele era "congênito". A explicação reside na ideia que Schmidt faz de um "verdadeiro realismo". O realismo verdadeiro de Julian Schmidt é aquele que sabe distinguir em cada coisa o que nela é "característico" e desse modo seu verdadeiro conteúdo (Inhalt), e que, no domínio artístico, sabe escolher os momentos que "reproduzem" (nachbilden) e "fazem surgir a vida" (das Leben hervorbringen). Julian Schmidt então diz que, se nomearem seu verdadeiro realismo "idealismo", não há propriamente equívoco, "pois a ideia da coisa", diz, "é também sua realidade". ${ }^{25}$ A conciliação é ela própria idealista: a ideia do verdadeiro idealista seria como a do verdadeiro realista porque as duas atingiriam a "essência" (Wesen) da coisa. O falso idealista produziria, nesse arranjo, ideias sem correspondência com a realidade, como as recusadas por Otto Ludwig.

Passo à conclusão, retomando Schiller.

\section{Conclusão}

A julgar pela insistência, nos três autores do realismo histórico, de afirmações como "representação de toda a vida no elemento da arte" (Fontane), de recusas a supostos artificialismos e ilusões, da transparência da realidade na arte (Otto Ludwig), de oposições entre verdades e fraudes (Julian Schmidt), reside aí não apenas uma base idealista, mas um conservadorismo estético. ${ }^{26}$ Esse conservadorismo adquire sentidos problemáticos sobretudo se se pensa que está vinculado a uma literatura posterior às de Büchner e Heine, por exemplo, hoje reconhecidas por um realismo menos distante dos significados realistas estabelecidos sobretudo com o século XX. São conhecidas, em relação ao realismo histórico, as acusações de uma literatura mais ou menos alienada, conformista, em que predominam as aparências. Não são despropositadas, antes pelo contrário. Mas não devem ser simplesmente associadas a uma "simplicidade" formal ou conteudística, que só se explica com critérios modernistas. 
Também não devem fazer pensar que a realidade dos realistas oitocentistas era uma realidade simples, menos ainda dizer que entendam a realidade da mesma forma. O paradoxo seria dizer que o realismo histórico não dá conta de sua realidade histórica. Seria só um paradoxo, não fosse também um problema mal formulado, já que em momento algum equivalem a realidade histórica e o realismo como realidade literária. A manutenção do idealismo é também uma manutenção da autonomia estética. Também nos programas realistas não equivalem realismo e realidade histórica.

Por fim, nesses programas, como se viu, conservam-se de Schiller ao menos dois dos três aspectos mencionados como preferências idealistas: a dificuldade com o elemento baixo na representação artística corresponde à dificuldade com o prosaísmo e a feiura em Fontane e à dificuldade com o naturalismo em Otto Ludwig; o pensamento polar que distingue em Schiller os "verdadeiros" realistas e idealistas também se mantém em Otto Ludwig e Julian Schmidt pressupondo realismos e idealismos equivocados. Em relação ao último aspecto, a avaliação negativa do presente, bastante clara em Schiller, a correspondência é menos evidente. $\mathrm{Na}$ verdade, não se deixa perceber de maneira simples. Em Fontane há uma satisfação com os tempos atuais ao menos no que respeita a avanços no conhecimento. A própria defesa do realismo em chave idealista parece conter uma avaliação positiva dos rumos históricos. Mas é necessário um estudo mais amplo, nessa matéria, e um estudo que inclua a análise de obras literárias do período, para afirmar algo menos impreciso. Se os romances do realismo histórico de algum modo traduzem as discussões de seus teóricos, é já outro assunto.

Concluindo: nos três autores do realismo histórico dos anos 1850 é visível uma estética dos meios-termos. Como disse, nem tão ao chão, nem tão ao céu. Daí a recorrência de adjetivos como "poético", "saudável", "artístico", "autêntico", que afirmam entretanto a preferência pelo realismo, que o diferenciam do idealismo, mas não excluem recorrências idealistas. Trata-se de amenizar os opostos como quem concilia Dom Quixote com Sancho Pança, e encontrar aí, entre o demasiado idealista e excessivo realista, um "verdadeiro" realismo.

Também em Schiller, afinal, são encontrados os caminhos do meio. Schiller não facilita e sugere, ao "gênio poetizante", algo como o "absoluto nos limites da humanidade". ${ }^{27}$ Para Schiller, o "ideal da bela humanidade" só pode surgir da união do ingênuo com o sentimental. Schiller aponta para os riscos do demasiado sentimental ou do demasiado ingênuo: em busca do absoluto, o sentimental pode ir além do homem e o ingênuo pode ficar aquém dele. ${ }^{28}$ Schiller alerta mais de uma vez para os riscos de uma dedicação exagerada aos domínios do pensamento, para o desprezo da experiência e do mundo sensível: são os riscos do poeta sentimental e assim os riscos do idealista; e alerta para os riscos do poeta ingênuo, que são os riscos do realista, os de seguir também ilimitadamente sua própria natureza.

Por isso, as obras-primas do gênero ingênuo normalmente têm por séquito as mais triviais e sórdidas cópias da natureza vulgar, e as obras principais do gênero sentimental, um numeroso exército de produções fantasiosas, como é facilmente demonstrável na literatura de qualquer povo. ${ }^{29}$

Nesse sentido está prevista também em Schiller a estética conciliadora que observamos nos programas do realismo histórico. O resultado estético, para Schiller, depende de um equilíbrio entre "elevar-se acima do real" e "permanecer limitado aos sentidos". ${ }^{30}$ Os dois são bem-vindos, o idealismo e o realismo, mas não devem ser exclusivos ou exagerados. 


\section{Notas de fim}

${ }^{1}$ Cf. Hugo Aust, Literatur des Realismus, Stuttgart, Metzler, 2000 (3ª ed.), p. 25.

2 Fritz Martini, sobretudo, autor do amplo estudo Deutsche Literatur im bürgerlichen Realismus 1848-1898, Stuttgart, Metzler, Poeschel, 1962.

${ }^{3}$ Der Briefwechsel zwischen Schiller und Goethe, edição de Emil Staiger, Frankfurt am Main, Insel, 1992 (8 ed.), p. 611-13.

${ }^{4}$ Cf. carta de Schiller a Wilhelm von Humboldt em 9 de janeiro de 1796. Friedrich Schiller, Briefe II 1795-1805, edição de Norbert Oellers, Frankfurt am Main, Deutscher Klassiker Verlag, 2002, p. 134-37.

${ }^{5}$ Cf. carta de Schiller a Goethe em 23 de agosto de 1794. Friedrich Schiller, Briefe I 1772-1795, ed. Georg Kurschẹidt, Frankfurt am Main, Deutscher Klassiker Verlag, 2002, p. 701-4. Aqui, Goethe seria exemplo da atitude ingênua e intuitiva, e ele próprio, Schiller, da sentimental e especulativa.

${ }^{6}$ Friedrich Schiller, Poesia ingênua e sentimental, trad. Márcio Suzuki, São Paulo, Iluminuras, 1991, p. 102.

${ }^{7}$ Idem, ibidem, p. 109.

${ }^{8}$ Idem, ibidem, p. 74.

${ }^{9}$ Idem, ibidem, p. 54.

10 Ver também, de Schiller, "Gedanken über den Gebrauch des Gemeinen und Niedrigen in der Kunst", in Theoretische Schriften, ed. Rolf- Peter Janz, Frankfurt am Main, Deutscher Klassiker Verlag, 2008, p. $452-459$.

${ }^{11}$ Friedrich Schiller, Poesia ingênua e sentimental, op. cit., p. 81.

12 Idem, ibidem, p. 91.

${ }^{13}$ Idem, ibidem, p. 61.

${ }^{14}$ Idem, ibidem, p. 85.

15 Penso em autores como Friedrich Theodor Viṣcher ou Julius Hermann von Kirchmann, que publica, em 1868 sua Asthetik auf realistischer Grundlage. O "meio-termo", nessa tradição, aparece já em Wilhelm Traugott Krug, que, em 1832, falava num "sintetismo estético" como resultado da combinação de um "realismo estetico" com um "idealismo estético".

$16 \mathrm{O}$ texto presente foi originalmente apresentado como fala na IX Jornada de Literatura Alemã da Faculdade de Filosofia, Letras e Ciências Humandas da Universidade de São Paulo, em 3 de dezembro de 2014. Não há diferenças signifiçantes entre a fala e o ensaio agora publicado. Oportunamente, o estudo deve ser ampliado, contemplando mais aspectos do realismo histórico de língua alemã e de sua teoria.

17 Os textos de Theodor Fontane, Otto Ludwig e Julian Schmidt foram consultados na edição de Gerhard Plumpe, Theorie des bürgerlichen Realismus, Stuttgart, Reclam, 1997.

18 Theodor Fontane, "Realismus", apud Plumpe, Theorie des bürgerlichen Realismus, op. cit., p. 142.

19 Idem, ibidem, p. 147. Tradução minha.

${ }^{20}$ Otto Ludwig, "Der poetische Realismus”, apud Plumpe, Theorie des bürgerlichen Realismus, op. cit., p. 14850 .

${ }^{21}$ Otto Ludwig atribui o conceito a Karl Wilhelm Ferdinand Solger (1780-1819).

22 Julian Schmidt, "Die Reaktion in der deutschen Poesie", apud Plumpe, Theorie des bürgerlichen Realismus, op. cit., p. 91-99.

${ }^{23}$ Friedrich Schiller, Poesia ingênua e sentimental, op. cit., p. 56.

24 Julian Schmidt, "Schiller und der Idealismus", apud Hans-Joachim Ruckhäberle; Helmuth Widhammer, Roman und romantheorie des deutschen Realismus, Kronberg, Athenäum, 1977, p. 89-98.

${ }^{25}$ Idem, ibidem, p. 93.

26 É possível pensar igualmente num conservadorismo político, cuja contraparte estética, outra vez, associa Schiller aos realistas da segunda metade do século XIX. Sabe-se da decepção de Schiller, "o poeta da liberdade e da justiça”, com os rumos da Revolução Francesa, sobretudo após a execução de Luís XV VI, e de sua predileção pela via estética, uma vez que "[...] para resolver na experiência o problema político é necessário caminhar através do estético, pois é pela beleza que se vai à liberdade" (Friedrich Schiller, A educação estética do homem, trad. Roberto Schwarz e Márcio Suzuki, Șão Paulo, Iluminuras, 1995, $3^{a}$ ed, p. 26). Por seu turno, com a desilusão revolucionária de 1848, as reivindicações de liberdade e nação da burguesia liberal alemã são substituídas pelo assentamento de um "realismo político" (a Realpolitik de August Ludwig von Rochau é de 1853 ) dependente em ampla medida do regime militar prussiano, até a instituicão do Império Alemão em 1871. São duas formas e contextos distintos, mas em ambos os casos, isto é, em Schiller e nos realistas posteriores a 1948 , as condições históricas se impõem.

${ }^{27}$ Friedrich Schiller, Poesia ingênua e sentimental, op. cit., p. 94.

28 O sentimental “[..] não se expõe apenas ao perigo de idealizar, mas também ao de ir além da própria possibilidade ou exaltar [schwärmen]. Esse erro da extravagâncía é fundado na propriedade específica de seu proceder, tanto quanto o erro oposto, a indolência, na maneira própria de agir do ingênuo. $O$ gênio ingênuo deixa, pois, a natureza imperar irrestritamente em si, e uma vez que a natureza é sempre dependente e necessitada em suas manifestações temporais isoladas, o sentimento ingênuo nem sempre permanecerá suficientemente exaltado para poder resistir às determinações contingentes do momento. O gênio sentimental, ao contrário, deixa a realidade para ascender a ideias e dominar sua matéria com livre espontaneidade; no entanto, visto que a razão, 
segundo sua lei, sempre se empenha pelo incondicionado, o gênio sentimental nem sempre permanecerá suficientemente sóbrio para manter-se de maneira constante e uniforme no interior das condições qụe o conceito de uma natureza humana implica, e às quais a razão tem de permanecer ligada, mesmo em seu mais livre atuar Isso poderia ocorrer apenas mediante um grau proporcional de receptividade, que, porém, é suplantada pela espontaneidade no gênio poético sentimental como igualmente suplanta a espontaneidade no gênio poético ingênuo. Por isso, se às vezes se sente a faltạ do espírito nas criações do gênio ingênuo, também amiúde em vão se pergunta pelo objeto nos frutos do gênio sentimental. Ambọs, pois, embora de modo inteiramente oposto, cairão no vazio; porque ambos, um objeto sem espírito e um jogo do espírito sem objeto, nada são no juízo estético". Idem, ibidem, 94-95.

${ }^{29}$ Idem, ibidem, p. 97.

${ }^{30}$ Cf. carta de Schiller em 14 de setembro de 1797 a Goethe. "Zweierlei gehört zum Poeten und Künstler: daß er sich über das Wirkliche erhebt und daß er innerhalb des Sinnlichen stehen bleibt. Wo beides verbunden ist, da ist aesthetische Kunst. Aber in einer ungünstigen formlosen Natur verläßt er mit dem Wirklichen nur zu leicht auch das Sinnliche und wird idealistisch und, wenn sein Verstand schwach ist, gar phantastisch: oder will er und muß er, durch seine Natur genöthigt, in der Sinnlichkeit bleiben, so bleibt er gern auch bei dem Wirklichen stehen und wird, in beschränkter Bedeutung des Worts, realistisch, und wenn es ihm ganz an phantasie fehlt, knechtisch und gemein. In beiden Fällen also ist er nicht aesthetisch." Friedrich Schiller, Briefe II 1795-1805, op. cit., p. 320-22. 